\title{
Shocking Aspects of Canadian Labor Markets
}

\author{
Tamim Bayoumi, Bennett Sutton, and \\ Andrew Swiston
}





\title{
IMF Working Paper
}

Western Hemisphere Department

Shocking Aspects of Canadian Labor Markets

Prepared by Tamim Bayoumi, Bennett Sutton, and Andrew Swiston ${ }^{1}$

March 2006

\begin{abstract}

\section{This Working Paper should not be reported as representing the views of the IMF.}

The views expressed in this Working Paper are those of the author(s) and do not necessarily represent those of the IMF or IMF policy. Working Papers describe research in progress by the author(s) and are published to elicit comments and to further debate.
\end{abstract}

We analyze the flexibility of the Canadian labor market across provinces in both an interand intra-national context using macroeconomic data on employment, unemployment, participation, and (for Canada) migration and real wages. We find that Canadian labor markets respond in a similar manner to their U.S. counterparts and are more flexible than those in major euro area countries. Within Canada, the results indicate that labor markets in Ontario and provinces further west are more flexible, particularly with regard to migration, while those further east are less so.

JEL Classification Numbers: E24, J21, J61

Keywords: Labor market, migration, economic flexibility

Author(s) E-Mail Address: tbayoumi@imf.org, bsutton@imf.org, aswiston@imf.org

\footnotetext{
${ }^{1}$ Many thanks to Jorg Decressin, Sam Ouliaris, and Chris Towe for insightful comments on earlier drafts. All remaining errors are our own.
} 


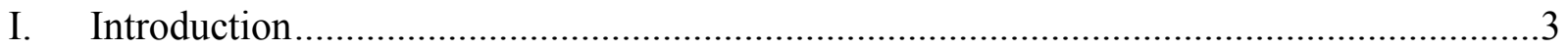

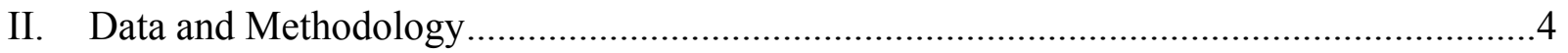

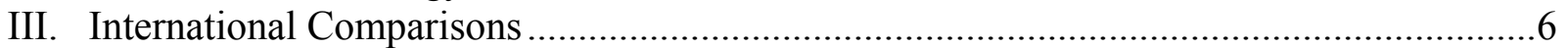

IV. Results Across Canadian Provinces............................................................................. 8

V. Extending the Canadian Model............................................................................ 9

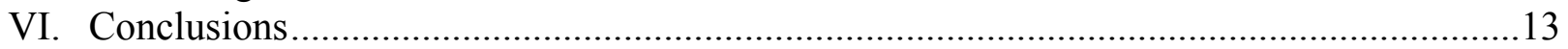

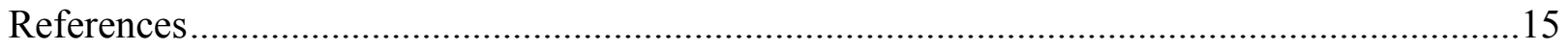

Table

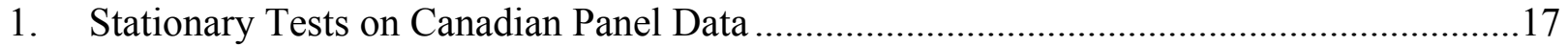

Figures

1. Labor Market Developments Across Canadian Regions, 1980-2004 .............................18

2. International Responses to Shocks in Employment Demand .........................................19

3. International Responses to Shocks in Employment Demand Including Economic

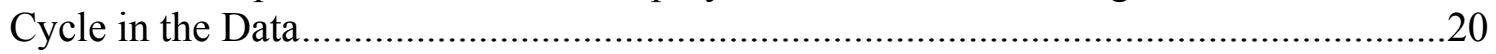

4. Canadian Regional Labor Market Adjustment ........................................................21

5. Canadian Labor Market Adjustment in Ontario, Québec ................................................22

6. Canadian Regional Labor Market Adjustment with Economic Cycle Included

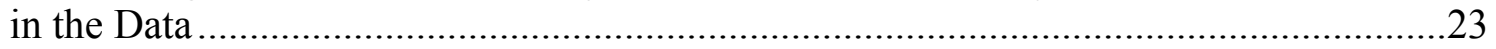

7. Canadian Regional Labor Market Adjustment with Migration Effects .............................24

8. Regional Adjustment with Migration Effects: New Specification ..................................25

9. Real Wages and Labor Adjustment: New Specification.............................................26

10. External Shocks and Labor Adjustment: New Specification........................................27

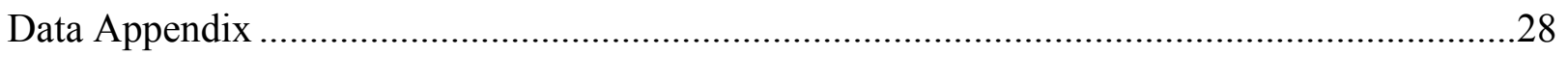




\section{INTRODUCTION}

Labor market flexibility is an important indicator of differences in economic performance across countries. In particular, greater flexibility of the labor market is generally regarded as one of the key differences explaining both the greater capacity of the United States to absorb adverse macroeconomic shocks compared, for example, to the euro area as well as the significant remaining difference in living standards between these two regions. ${ }^{2}$

Canada's susceptibility to external shocks and highly regionalized economic structure put an additional premium on economic flexibility, including in labor markets. Exchange rate flexibility helps the economy to buffer external disturbances, while its regional diversity underlines the importance of being able to shift workers within the country. Focusing on the second topic, this paper examines Canada's labor mobility from a range of perspectives, including a comparison of Canada's labor market dynamics with those of other countries. In addition, as the generosity of Canadian Employment Insurance (EI) payments is greater and more easily accessible in locations where unemployment is high, a particular focus of the paper is on the degree to which labor mobility appears to differ within Canada, and how it appears to depend on prevailing regional labor market conditions.

The approach in this paper follows and extends earlier macroeconomic work on measuring labor adjustment within countries. In particular, Blanchard and Katz (1992) analyzed U.S. labor market flexibility by first adjusting for the aggregate cycle from data on individual states and then running vector autoregressions (VARs) on state-specific changes in employment, unemployment, and the participation ratio. They found that local U.S. labor markets appeared to adjust relatively rapidly to acyclical shocks, with migration playing a key role in this process. By contrast, using the same methodology, Decressin and Fatas (1995) found that labor adjustment across European regions was less flexible than in the United States. This difference in results suggests that this methodology provides a useful method of comparing labor market characteristics across regions.

Canada's comprehensive data on individual provinces also allow the role of migration and of real wages in to be examined explicitly within the methodology. This provides information on the relative importance of changes in relative remuneration and in migration - prices and quantities - in equilibrating provincial labor markets. In addition, recognizing the key role of external shocks in determining regional trends, the approach is adapted to examine if labor market adjustment differs depending on the source of disturbances. This allows a much fuller view of the drivers of labor market adjustment than was possible in the work discussed above.

\footnotetext{
2 Labor market reform, including raising participation rates to boost output, is a key component in the euro area's Lisbon structural reform agenda (European Commission, 2005). For estimates of the possible benefits from such reforms on flexibility and output, see Bayoumi, Laxton, and Pesenti (2004) and Gersbach (2003).
} 
The rest of this paper is organized as follows. The next section discusses the basic specification and how it is implemented. Section III reports the results for international data and section IV those from Canadian provinces. Section V then discusses extensions to the basic model for Canada, while Section VI concludes.

\section{Data ANd Methodology}

Annual data on employment, unemployment, and the participation ratio were collected for individual Canadian provinces and regions in other countries (see the Appendix for details on the data). ${ }^{3}$ The other countries were the United States (where the data cover all 50 states) and three EU members, the "core" countries of France and Germany, as well as Spain, which is part of the rapidly growing periphery (the European data are for standard Eurostat regions). ${ }^{4}$ In addition, series were also collected on Canadian provincial real wages and net migration to provide more detail of the channels for Canadian labor market adjustment.

Labor market conditions differ widely across Canadian regions. Figure 1 graphs some basic data for three Canadian regions, the western, central, and eastern "Atlantic" provinces." Over the last 15 years, employment growth has been generally faster as one moves from east to west, unemployment rates have been lower, and participation rates higher. In addition, there has been a steady net migration out of the Atlantic provinces and into central and western Canada. ${ }^{6}$ These differences in labor market characteristics in turn partly reflect the regionally diverse structure of the Canadian economy, as the relative success of differing industries translate into long-term labor market trends. ${ }^{7}$

Following earlier authors, the aggregate cycle is taken out of the data by regressing (say) the logarithm of the current change in employment on a constant term and the

\footnotetext{
${ }^{3}$ Data start in the mid-1970s for the United States and Canada, and in the mid-1980s for the Europeans.

${ }^{4}$ Data were also collected on a number of other European countries, but were too fragmented to be useable.

${ }^{5}$ The west comprises Alberta, British Columbia, Manitoba, and Saskatchewan. The center is Ontario and Québec. The Atlantic provinces are Newfoundland, New Brunswick, Nova Scotia, and Prince Edward Island.

${ }^{6}$ Overall migration can be divided into immigration into Canada from abroad (which has been large by industrial country standards) and movements of people within the country. The former are heavily concentrated in Ontario and some western provinces, while there is a strong tendency for existing residents to move west. Microeconomic evidence indicates that foreign immigrants are older and more likely to be married than the general population, characteristics that make then less likely to move once settled within the country (Lin, 1998).

${ }^{7}$ See the discussion in IMF (2005) Box 2 and in Klyuev and Luzio (2006).
} 
logarithm of the change in national employment. ${ }^{8}$ As this is done for all variables, the approach identifies labor market responses to acylical shocks, allowing the analysis to focus on how labor markets respond to local disturbances. As a check on the robustness of the analysis, results using the raw data — which include the national cycle — are also reported.

Labor market adjustment is assessed by tracing responses to changes in the demand for workers. In earlier work, these changes in demand are identified by running a VAR involving two lags of the annual change in the logarithm of employment $(\Delta e)$, the logarithm of the employment ratio (emp, the ratio of employment to the labor force, which equals one minus the unemployment rate), and the logarithm of the participation rate ( $p$, the ratio of the labor force to population 15-64). Formally:

$$
\begin{aligned}
& \Delta e=\alpha+\alpha_{e 1} \Delta e_{-1}+\alpha_{e 2} \Delta e_{-2}+\alpha_{e m p 1} e m p_{-1}+\alpha_{e m p 2} e m p_{-2}+\alpha_{p 1} p_{-1}+\alpha_{p 2} p_{-2}+\varepsilon_{\Delta e} \\
& e m p=\beta+\beta_{e 1} \Delta e_{-1}+\beta_{e 2} \Delta e_{-2}+\beta_{e m p 1} e m p_{-1}+\beta_{e m p 2} e m p_{-2}+\beta_{p 1} p_{-1}+\beta_{p 2} p_{-2}+\varepsilon_{e m p} \\
& p=\gamma+\gamma_{e 1} \Delta e_{-1}+\gamma_{e 2} \Delta e_{-2}+\gamma_{e m p 1} e m p_{-1}+\gamma_{e m p 2} e m p_{-2}+\gamma_{p 1} p_{-1}+\gamma_{p 2} p_{-2}+\varepsilon_{p} .
\end{aligned}
$$

Rewriting in matrix terms:

$$
y_{t}=A_{1} y_{t-1}+A_{2} y_{t-2}+\varepsilon_{t}
$$

where $y_{t}{ }^{\prime}=\left(\Delta e_{t}, e m p_{t}, p_{t}\right), \varepsilon_{t}{ }^{\prime}=\left(\varepsilon_{\Delta e t}, \varepsilon_{e m p t}, \varepsilon_{p t}\right)$, and $\mathrm{A}_{1}$ and $\mathrm{A}_{2}$ are square matrices of coefficients.

Note that the logarithm of employment less the logarithm of the employment ratio and participation ratio sum to the population 15-64:

$$
e-e m p-p=e-(e-l a b)-(l a b-p o p)=p o p
$$

where $l a b$ is the labor force and pop is the population 15-64. As a result, any adjustment unexplained by the model is assumed to reflect changes in population, presumably largely through migration.

Disturbances to the employment equation $\left(\varepsilon_{\Delta e}\right)$, ordered first in the VAR, are assumed to reflect changes in labor demand. Supply-side effects are assumed to occur through shocks to the employment ratio and participation ratios $\left(\varepsilon_{e m p}\right.$ and $\left.\varepsilon_{p}\right)$ and to feed through to employment with a lag. In addition, as employment is entered in changes while the employment ratio and participation ratio are included in the VAR in levels, the specification

\footnotetext{
${ }^{8}$ Similar results were found using an alternative procedure, in which the logarithm of (say) the national change in employment was subtracted from the logarithm of the change in employment for each region. This suggests that the precise method by which the national cycle is taken out of the data is not driving the results.
} 
implies that employment across regions can change permanently while both the employment ratio and participation rate eventually return to their initial value. The implicit assumption that the employment and participation ratios are stationary implies that all long-run adjustment occurs through changes in population via migration.

Analysis of the Canadian data casts doubt on the assumption that the employment and participation ratios are stationary. Table 1 reports two tests of the stationarity of the Canadian panel data. Consistent with the assumptions discussed above, the logarithm of employment is found to be nonstationary. ${ }^{9}$ Results for the employment and participation ratios are less clearcut, with the latter, in particular, appearing most likely nonstationary (consistent with the long-term differences in behavior across regions seen in Figure 1).

Accordingly, this paper focuses on a specification in which unemployment and participation play a role on long-term adjustment. This is accomplished by including the employment and participation ratios in the VAR in first differences rather than levels. In the notation of equation (2):

$y_{t}{ }^{\prime}=\left(\Delta e_{t}, \Delta e m p_{t}, \Delta p_{t}\right)$ and $\varepsilon_{t}{ }^{\prime}=\left(\varepsilon_{\Delta e t}, \varepsilon_{\Delta e m p t}, \varepsilon_{\Delta p t}\right)$

To facilitate comparisons with earlier work, we also report results from the "traditional" specification used by earlier authors, which turn out to provide broadly similar conclusions but fit the data less well.

An alternative approach to estimating the VAR using first differenced data would be to estimate a VECM, in which a VAR in first differences is augmented with "error correction" terms that represent the tendency for the model to return to a long-term equilibrium defined in level terms. This approach was not chosen as the focus of this analysis is on the dynamic adjustment of labor markets over the first few years after a shock, rather than on identifying long-term adjustment processes.

\section{INTERNATIONAL COMPARISONS}

Figure 2 reports responses to regional employment shocks in Canada, the United States, Spain, France, and Germany. As results for France and Germany were found to be somewhat unstable, the VAR combines the data for these two countries. ${ }^{10}$ The top panels report responses using the new specification, while the bottom panels use the traditional approach in which the impact of the employment ratio and participation ratio are assumed to fade over time. In this and all subsequent graphs, the upper solid line reports the response of

\footnotetext{
${ }^{9}$ Real wages are found to be nonstationary and migration stationary, and thus are included in extended VARs in first differences and levels, respectively.

${ }^{10}$ National cycles are subtracted from each country separately.
} 
the logarithm of employment over 10 years to a shock in demand for workers. The lightly shaded area at the bottom of the graph represents the amount of this adjustment explained by the employment ratio (i.e., the negative of changes in the unemployment rate) and the more darkly shaded area shows the additional adjustment from the participation ratio.

Focusing on the top left-hand graph, a typical acyclical annual disturbance to employment in a U.S. state is around 1 percent of overall jobs. This rises over the next few years to its long-term value of $13 / 4$ percent. About one-quarter of the initial shock is absorbed by a rise in the employment ratio (i.e., a fall in unemployment). This effect rises slightly in the second year before falling to become a minimal part of the adjustment process over the longer term. Changes in participation play a more important role in adjustment. The rise in the participation ratio explains the lion's share of initial change in employment, and this effect stays relatively stable over time. Changes in population play a minor role in the initial response but rise over time as employment expands, playing a major role in the long-term expansion of employment.

Comparing the results from the new specification across countries, it appears that Canada's labor market adjusts in a broadly similar manner to the United States, while changes in population play a much less important role in EU countries. The graphs in the top panel of Figure 2 suggest that all four countries are subject to similarly sized acyclical employment shocks and similar initial responses. In particular, the employment and participation ratios play an important role in the initial adjustment, and this initial impact falls only slightly over time. ${ }^{11}$

The main difference across countries is in the response of employment and population. In Canada and the United States, the initial shock in regional employment results in a further increase over the next few years as population expands. By contrast, in the EU countries some of the initial gain in employment is lost over time as population fails to expand further. These results suggest that changes in population (i.e., migration) play a much more important role in labor market adjustment in North America than in Europe. This corresponds to the general view that North American labor markets are more flexible than their European counterparts, a view supported by OECD structural indicators. ${ }^{12}$

Results from the traditional specification, reported in the bottom panels of Figure 2, produce a broadly similar picture. With the impact of the employment ratio and participation

\footnotetext{
${ }^{11}$ Within the adjustment process, unemployment (the negative of the employment ratio) plays a more prominent role in Spain, while discouraged workers (i.e., changes in the participation ratio) appear more important in the United States, Canada, and (more surprisingly) France and Germany. These patterns may reflect differing labor market incentives, for example with regard to the generosity and duration of unemployment benefits.

12 OECD (2005).
} 
ratio constrained to dwindle over time, these variables play a less important role in long-term adjustment. Despite this difference, changes in population remain a much more important adjustment mechanism in North America than in Europe. The smaller role played over time by unemployment and participation is largely counterbalanced by smaller longer-term responses in employment. As a result, the role of population changes continues to be quite different across countries, with North American labor markets continuing to look more flexible than EU countries.

A possible concern is that the results to date may reflect the elimination of the national cycle from the data. To investigate this issue, the model was rerun using the raw data that includes the national cycle (Figure 3). Again, the United States and Canada appear to be able to shift employment and population across regions much more effectively than the EU countries of France, Germany, and Spain in both specifications. Spain is also notable for the size of its cyclical shocks, possibly reflecting the volatility associated with rapid economic convergence. Thus, the clear differences in the adjustment mechanism in North America compared to Europe remain when the national cycle is included in the data.

In short, greater migration appears to distinguish more flexible labor markets in North America from their less flexible European counterparts under all specifications. This suggests that the model is capable of robustly identifying differences in labor market behavior across countries. In what follows, we will repeat this approach, focusing on how labor market behavior varies across regions within Canada.

\section{Results Across Canadian Provinces}

To analyze labor adjustment within Canada, results are reported for the three regions identified earlier - the western, central, and Atlantic provinces. In addition to the differences in labor market characteristics, these regions have diverse economic structures.

- $\quad$ The western provinces are specialized in raw material production, whose remote location could slow the pace of labor adjustment.

- In the central provinces, which represent the manufacturing heartland, adjustment could be affected by their economic size (Ontario and Québec represent around onethird of national employment each), as well as Québec's cultural differences from the rest of Canada.

- $\quad$ Finally, in the relatively small Atlantic provinces that have been characterized by declining industries, migration may have been discouraged by a dwindling pool of the young and relatively mobile as well as by more easily accessed and more generous unemployment benefits.

Results from the new specification, reported in the top panels of Figure 4, suggest significant differences in labor market flexibility across Canadian regions. In particular, 
changes in population become a more important factor in labor market adjustment as one moves west. Looking across regions, the results indicate that:

- $\quad$ The western provinces face large employment shocks that grow over time, with population change playing a dominant role in the adjustment.

- While the Atlantic provinces face similarly sized initial shocks to those in the west, employment does not expand thereafter due to the more limited role for population change - although the population response remains larger than in EU countries.

- $\quad$ The central provinces face smaller employment shocks, presumably because their size in the national labor market and diversity of industries means that more of the adjustment occurs within the province. ${ }^{13}$ Employment rises mildly over time, but much less than in the west, and population change plays a less important role in adjustment.

- The traditional specification produces qualitatively similar results to the new one.

Given the importance of the central provinces for Canada's economy, the model was run separately for Ontario and Québec (Figure 5). The results suggest that Ontario's labor markets are significantly more flexible than those in its eastern neighbor. Both provinces face similar sized employment disturbances and initial responses. However, employment expands over time and population change plays a dominant role in long-term labor market adjustment in Ontario, while in Québec employment remains relatively stable over time and population change plays a minimal role. This result, which is consistent across the two specifications, corresponds to microeconomic evidence that French-speakers and residents of Québec are less likely to migrate than others (Audas and MacDonald, 2003).

Similar results are found when the Canadian cycle is included in the data (Figure 6). The sizes of employment shocks across the regions are more similar, underlining the potential importance of economic size in explaining the size of acylical shocks in Ontario and Québec. In addition, the responses are more dependent on whether shocks to the employment and participation ratios are considered permanent or not, with the former assumption producing less cyclical responses.

\section{Extending the Canadian Model}

The depth of Canadian provincial data set allows examination of three further issues - the role of migration, real wages, and external disturbances in labor market adjustment. Including migration in the model allows a direct test of the implicit assumption

\footnotetext{
13 Based on data on mobility across 71 "economic regions," people are some two-and-a-half times more likely to move within a province compared to between one province and another (Audas and MacDonald, 2003).
} 
that it is the main mechanism behind the adjustment ascribed to population change. Real wage data can be used to examine whether employment shocks do indeed largely reflects labor demand shocks, as well as on the relative importance of prices and quantities in adjustment across provinces. Finally, identification of responses to external developments provides insights into whether labor market adjustment differs significantly depending on the nature of the shock.

As Canada collects data on net migration by province, it is possible to directly observe the role of movement of workers in labor market adjustment. Accordingly, the following variable was included in the VAR:

$$
\operatorname{mig}_{t}=\log \left(\frac{\text { pop }_{t}}{\text { pop }_{t-1}}\right)-\log \left(\frac{\text { pop }_{t}-m_{t}}{\operatorname{pop}_{t-1}}\right)
$$

where pop is the population 15-64 and $m$ is net inward migration. This term measures the change in the growth of population caused by migration, and hence its impact on labor market adjustment. ${ }^{14}$

It should be noted that there have been a series of microeconomic studies looking at migration in Canada, including the impact of the EI program on such mobility. They indicate that migrants are most likely to be young, unmarried, better educated, and English-speaking (Lin, 1995). Migration is also boosted by larger wage differentials and is more likely the shorter the distance involved.

The evidence on the impact of EI on labor mobility is mixed (see Day and Winer, 1994 for a review of work through the early 1990s). However, recent studies generally suggest a modest negative effect, particularly for those with limited attachment to the labor force (Audas and MacDonald, 2003; Day and Winer, 2001). ${ }^{15}$

Adding migration $\left(\mathrm{mig}_{t}\right)$ to the model allows a test of the overidentifying restriction that the adjustment that is not ascribed to changes in the employment ratio and participation rate reflects migration. This is achieved by amending the initial VAR to include migration as the final variable. Using the format of equation (2), the model is:

$$
y_{t}{ }^{\prime}=\left(\Delta e_{t}, \Delta e m p_{t}, \Delta p_{t}, \text { mig }_{t}\right) \text { and } \varepsilon_{t}{ }^{\prime}=\left(\varepsilon_{\Delta e t}, \varepsilon_{\Delta e m p t}, \varepsilon_{\Delta p t}, \varepsilon_{m i g t}\right)
$$

\footnotetext{
${ }^{14}$ The migration data include those under 15 , and hence are not strictly compatible to the data on participation. However, these differences in definition are unlikely to have a major effect on the empirical results.

${ }^{15}$ Finnie (2000), however, concludes that EI may have improved mobility by providing resources to the unemployed.
} 
Migration is ordered last in the VAR as it is likely that people become unemployed or move out of the labor force before deciding to relocate their home.

The results from this model are reported in Figure 7. The impact of migration on the adjustment process (the relatively dark area) is added to those from the employment ratio and participation ratio. Given the identity noted in equation (3), these three variables should sum to the change in employment, which is also graphed. The overidentifying restriction is much more closely satisfied for the new specification than the traditional one, confirming that participation and unemployment probably play a role in long-term labor market adjustment. ${ }^{16}$

Consistent with the behavior inferred above, the results from the extended model suggest that migration is the major source of long-term labor market adjustment in the western provinces and Ontario, but is less important further east. In particular, in the western provinces migration represents some two-thirds of long-term labor market adjustment. For Ontario, it reflects over half of long-term adjustment. Further east, however, the results imply that migration is a significantly less important labor adjustment channel.

The dynamics of the other shocks in the system were also examined. Figure 8 reports the level responses of all variables to the four shocks in the system. In addition to the employment shock already discussed, this involves shocks to the employment ratio, the participation ratio, and migration. The employment ratio shock identifies a standard discouraged worker effect, in which people switch between being unemployed and dropping out of the labor force, with little impact on employment or migration. The shock to the participation ratio identifies a "discouraged migrant effect," in which individuals who are not in the labor force leave a province, boosting participation. This is followed by a fall in employment, but a small increase in the employment ratio. Finally, inward migration tends to be associated with subsequent increases in employment and participation-migrants move to places with jobs and join the work force.

The model was next expanded to include real wages across provinces. ${ }^{17}$ The response of real wages to a employment shocks can help to identify if it represents a labor demand shocks (in which case the impact on real wages should be positive) or changes in labor supply (when the response of real wages should be negative). The real wage response was identified by including the change in the logarithm of real wages directly after the change in the logarithm of employment. In the terminology of equation (2), the model becomes:

$y_{t}{ }^{\prime}=\left(\Delta e_{t}, \Delta w_{t}, \Delta e m p_{t}, \Delta p_{t}, m i g_{t}\right)$ and $\varepsilon_{t}{ }^{\prime}=\left(\varepsilon_{\Delta e t}, \varepsilon_{\Delta w t}, \varepsilon_{\Delta e m p t}, \varepsilon_{\Delta p t}, \varepsilon_{m i g t}\right)$

\footnotetext{
${ }^{16}$ The results of the traditional specification are particularly problematic for the Atlantic provinces.

${ }^{17}$ Real wages are defined as income from employment divided by employment and the provincial CPI.
} 
In addition, as migration is also included in the specification, the role of real wages (i.e., changes in relative prices) as against migration (i.e., changes in the available work force) in labor adjustment can be examined. This is done by comparing the results of the full VAR with a version in which the dynamic effects of real wages on adjustment is switched off. This is achieved by dropping the equation for real wages from the VAR while continuing to include the lagged real wage terms in the independent variables, thereby making the lagged real wage terms exogenous. The model thus becomes:

$y_{t}=A_{1} z_{t-1}+A_{2} z_{t-2}+\varepsilon_{t}$

$y_{t}{ }^{\prime}=\left(\Delta e_{t}, \Delta e m p_{t}, \Delta p_{t}, \operatorname{mig}_{t}\right), z_{t}{ }^{\prime}=\left(\Delta e_{t}, \Delta w_{t}, \Delta e m p_{t}, \Delta p_{t}, m i g_{t}\right), \varepsilon_{t}{ }^{\prime}=\left(\varepsilon_{\Delta e t}, \varepsilon_{\Delta e m p t}, \varepsilon_{\Delta p t}, \varepsilon_{m i g t}\right)$, and $A_{1}$ and $A_{2}$ are matrices of coefficients.

The results suggest that the model does identify labor demand shocks. The upper panels of Figure 9 show the results from the extended specification in which the change in the logarithm of real wages is included in the VAR. As can be seen from the dashed line, real wages rise in response to positive employment shocks - consistent with them being changes in labor demand - while the responses of the other variables are similar to those reported in Figure 7. In addition, the size of the percentage changes in real wages appear relatively small - between one-quarter and one-third of the change in employment — suggesting that real wages are unlikely to play a major role of labor market adjustment.

The lower panels of Figure 9, which report the results from the same VAR but with the real wage terms made into exogenous variables, also suggest and that real wages play a relatively minor role in regional labor market adjustment in Canada. The difference between the upper and lower panels in the Figure reflects the role played by real wages in labor market adjustment. The similarity of the responses across the panels suggests that long-term labor market adjustment appears to occur mainly through altering population via higher migration between provinces rather than through changes in relative wages. Similar results are found using alternative data and specifications.

The final extension of the model investigates the possibility that labor markets respond differently to different types of shocks. This is examined by taking the specification that excludes real wages and migration (to conserve degrees of freedom) and including as the first three variables in the VAR changes in the logarithm of real nonenergy commodity prices in U.S. dollars $\left(p_{n e c}\right)$, real energy commodity prices ( $p_{e n}$, also in U.S. dollars), and the real effective exchange rate (reer). In the terminology of equation (2):

$y_{t}{ }^{\prime}=\left(\Delta p_{\text {nect }}, \Delta p_{\text {ent }}, \Delta\right.$ reer $\left._{t}, \Delta e_{t}, \Delta e m p_{t}, \Delta p\right), \varepsilon_{t}{ }^{\prime}=\left(\varepsilon_{\Delta p n e c t}, \varepsilon_{\Delta p e n t}, \varepsilon_{\Delta r e e r t}, \varepsilon_{\Delta e t}, \varepsilon_{\Delta e m p t}, \varepsilon_{\Delta p t}\right)$

The responses to the associated shocks in the first three equations trace out labor market adjustment to changes in nonenergy commodity price shocks, oil price shocks that are not 
linked to nonenergy commodity prices, exchange rate changes not linked to commodity price developments, as well as other shocks to labor demand. ${ }^{18}$

External price shocks produce generally similar adjustment patterns to other labor demand shocks, suggesting labor market responses are largely independent of the nature of disturbances. Figure 10 reports results from the new specification. The thin lines, which trade out the response of the relevant relative prices, indicate that nonenergy commodity prices and exchange rate shocks are relatively transient, while oil shocks have a more permanent component. Nonenergy and energy commodity price shocks increase employment in the west with more minor effects elsewhere while exchange rate shocks have more significant effects in all regions. What is striking, however, is that the regional patterns to labor adjustment identified earlier-larger employment shocks in the west resulting in significant changes in population, with less mobility elsewhere-generally holds regardless of the nature of the shock.

\section{Conclusions}

This paper has examined Canada's labor market flexibility from an inter- and intranational perspective. The approach follows that of earlier work on the United States and Europe. A particular focus has been examining the robustness of the results to alternative methods of measuring the data and specification of the model. In addition, the comprehensive nature of Canadian provincial data was used to extend the analysis, allowing greater insights into the labor adjustment process.

In the international dimension, the results suggest that Canada has a relatively flexible labor market. In common with the United States, migration plays a significant role in the adjustment to labor demand shocks. By contrast, this mechanism is much less important in Spain, France, and Germany. These differences in behavior are robust across a range of assumptions and appear to be the key to explaining differing levels of flexibility across countries.

Labor markets within Canada seem to become more flexible as one moves to the west. Migration plays a much more important role in labor market adjustment in the western provinces than the Atlantic ones. Turning to the central provinces of Ontario and Québec, the evidence suggests that Ontario has a significantly more flexible labor market than its neighbor, consistent with microeconomic evidence on migration. Further analysis indicates that migration appears to be the main process through which labor markets adjust over time, with real wage differentials being a minor factor. Finally, the adjustment process appears relatively similar across macroeconomic disturbances. In short, labor adjustment appears very different east and west of the Ottawa river.

\footnotetext{
18 An attempt was also made to identify shocks from U.S. activity, but the close link between the U.S. and Canadian cycles made identification problematic.
} 
What is the role of policies in improving labor market flexibility? In Europe, the focus has been on a range of policies, including minimum wages, union representation, unemployment and social benefits, and restrains on moving houses. In Canada, whose labor and other markets are relatively flexible, the focus of discussion has been the EI system.

While the macroeconomic analysis reported here cannot directly identify the reasons for the observed differences in labor market flexibility across Canadian regions, both the inter- and intra-national results suggest that the key difference in labor market flexibility is the role played by migration. Empirical research on Canada suggests that economic opportunities, cost of migration, age, and language are the most important determinants of inter-provincial migration. While EI appears to play a more minor role, eliminating differences in eligibility and benefits across localities would tend to reduce the differences in labor market flexibility across regions identified in this paper. 


\section{REFERENCES}

Audas, Rick, and James McDonald, "Employment Insurance and Geographic Mobility: Evidence from the SLID,” SRDC Working Paper Series 03-03 (Ottawa: University of Brunswick Social Research and Demonstration Corporation).

Bayoumi, Tamim, Douglas Laxton, and Paolo Pesenti, 2004, "Benefits and Spillovers of Greater Competition in Europe: A Macroeconomic Assessment," CEPR Discussion Paper No. 4481 (London: Centre for Economic and Policy Research).

Blanchard, Olivier, and Lawrence Katz, 1992, "Regional Evolutions," Brookings Papers on Economic Activity, No. 1, pp. 1-75.

Day, Kathleen, and Stanley Weiner, 1994, "Internal Migration and Public Policy," in Issues in the Taxation of Individuals, ed. by A. Masgrove (Toronto: University of Toronto Press).

— 2001, "Policy-Induced Migration in Canada: An Empirical Study," Carleton University Working Paper 2001-08, Ottawa.

Decressin, Jorg, and Antonio Fatas, 1995, "Regional Labor Market Dynamics in Europe," European Economic Review, Vol. 39 December, pp.1627-55.

European Commission, 2005, "Integration Guidelines for Growth and Jobs (2005-08)"; Communication to the Spring European Council.

Finnie, R., 2000, "Who Moves? A Panel Logit Model Analysis of Inter-provincial Mobility in Canada," Statistics Canada Analytic Studies Branch Research Paper 142 (Ottawa: Statistics Canada).

Gersbach, 2003, "Structural Reforms and the Macroeconomy: The Role of General Equilibrium Effects," CEPR Discussion Paper 4043 (London: Centre for Economic and Policy Research).

International Monetary Fund, 2005, Canada: 2005 Article IV Consultation-Staff Report; Staff Statement; and the Public Information Notice on the Executive Board Discussion for Canada, IMF Country Report 05/118, Washington.

Lin, Zhengxi, 1995, Interprovincial Labor Mobility in Canada: The Role of Unemployment Insurance and Social Assistance, HRDC Unemployment Insurance Evaluation Series 21 (Ottawa: Human Resources Development Canada). , 1998, Foreign-Born versus Native-Born Canadians: A Comparison of their InterProvincial Labour Mobility, Statistics Canada Analytic Studies Branch Research Paper 125 (Ottawa: Statistics Canada). 
Luzio, Rodolfo, and Vladimir Klyuev, 2006, "Regional Dimensions of the Canadian Economy," unpublished paper available from the authors and forthcoming in International Monetary Fund Country Report, Canada: Selected Issues

OECD, 2005 Economic Policy Reforms: Going for Growth (OECD: Paris, France). 
Table 1. Stationary Tests on Canadian Panel Data

(p-values)

\begin{tabular}{lccc}
\hline & $\begin{array}{c}\text { Null: Unit Root } \\
\text { Inverse Fisher } \\
\text { Chi-square Test }\end{array}$ & Null: No Unit Root & Implication \\
\hline $\begin{array}{lcc}\text { Log employment } \\
\Delta \text { Log employment }\end{array}$ & 0.99 & $0.00 * *$ & Non-Stationary \\
& $0.00 * *$ & 0.88 & Stationary \\
Log employment ratio & 0.18 & 0.32 & Ambiguous \\
$\begin{array}{l}\text { Log participation rate } \\
\text { Migration }\end{array}$ & 0.07 & $0.00 * *$ & Non-Stationary \\
Log real wage & $0.00 * *$ & 0.57 & Stationary \\
$\Delta$ Log real wage & 0.83 & $0.00 * *$ & Non-Stationary \\
\hline
\end{tabular}

Notes: One and two asterisks indicate the result is significant at the 1 and 5 percent levels, respectively. 
Figure 1. Labor Market Developments Across Canadian Regions, 1980-2004

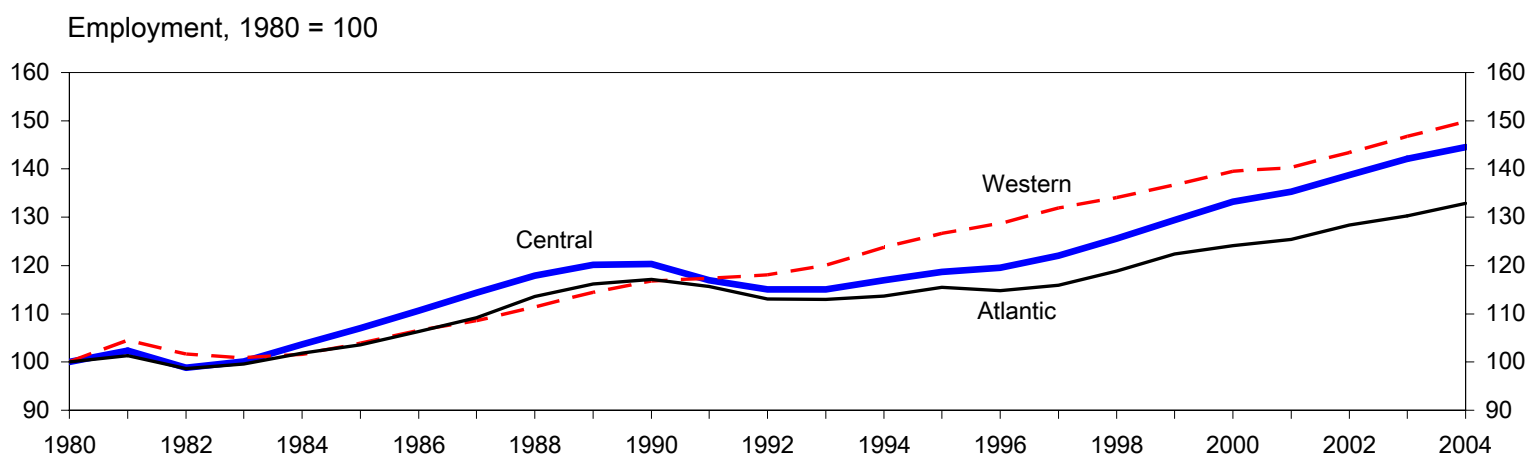

Unemployment rate, in percent

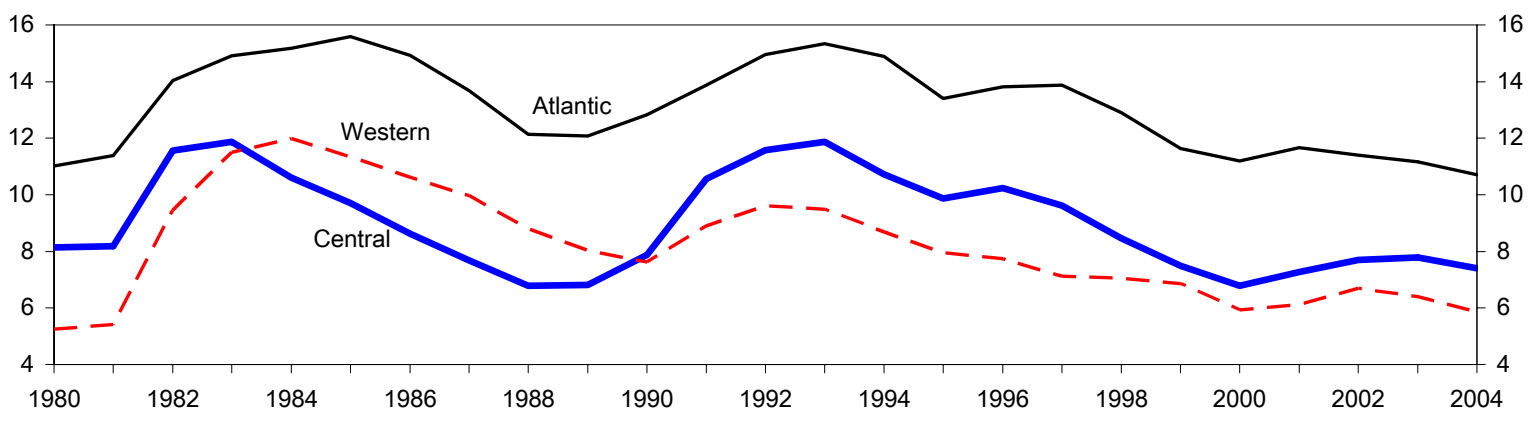

Labor force participation rate, in percent

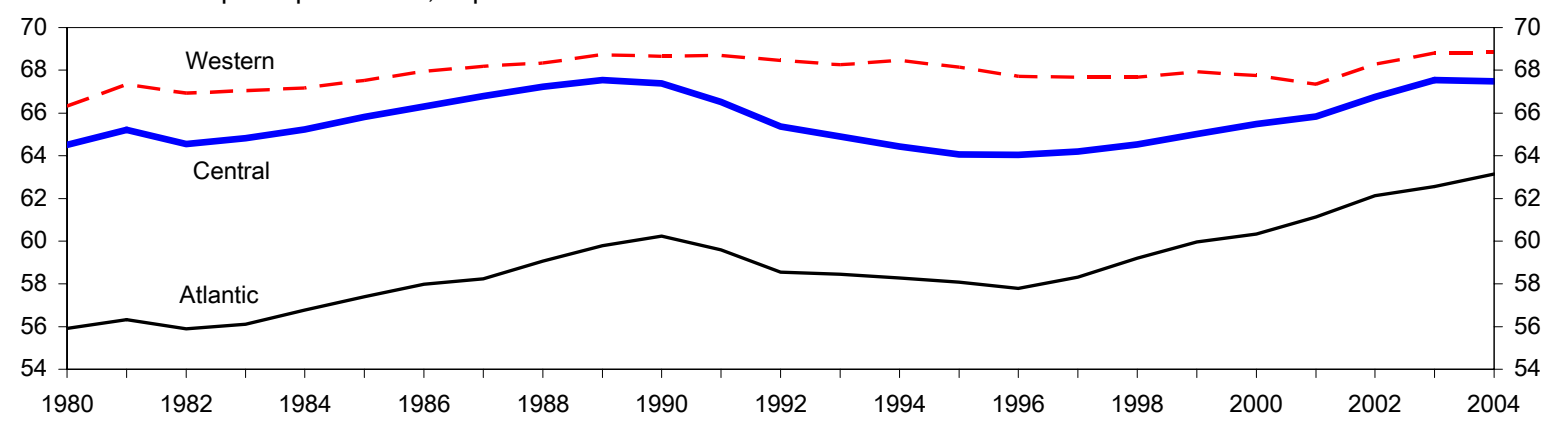

Net migration inflows (percent of working-age population)

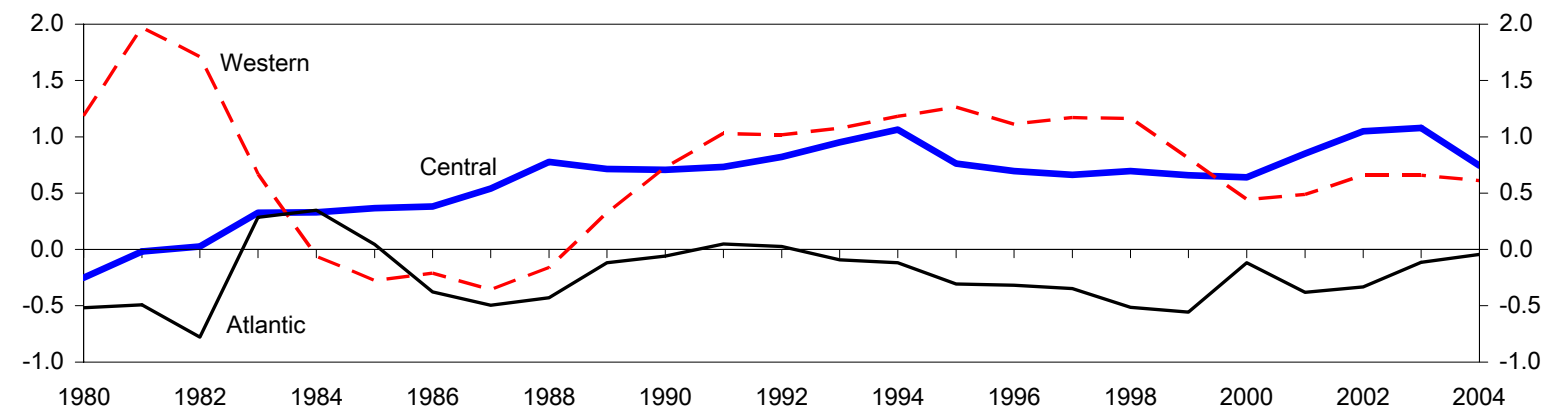

Sources: Haver Analytics; and Fund staff calculations. 

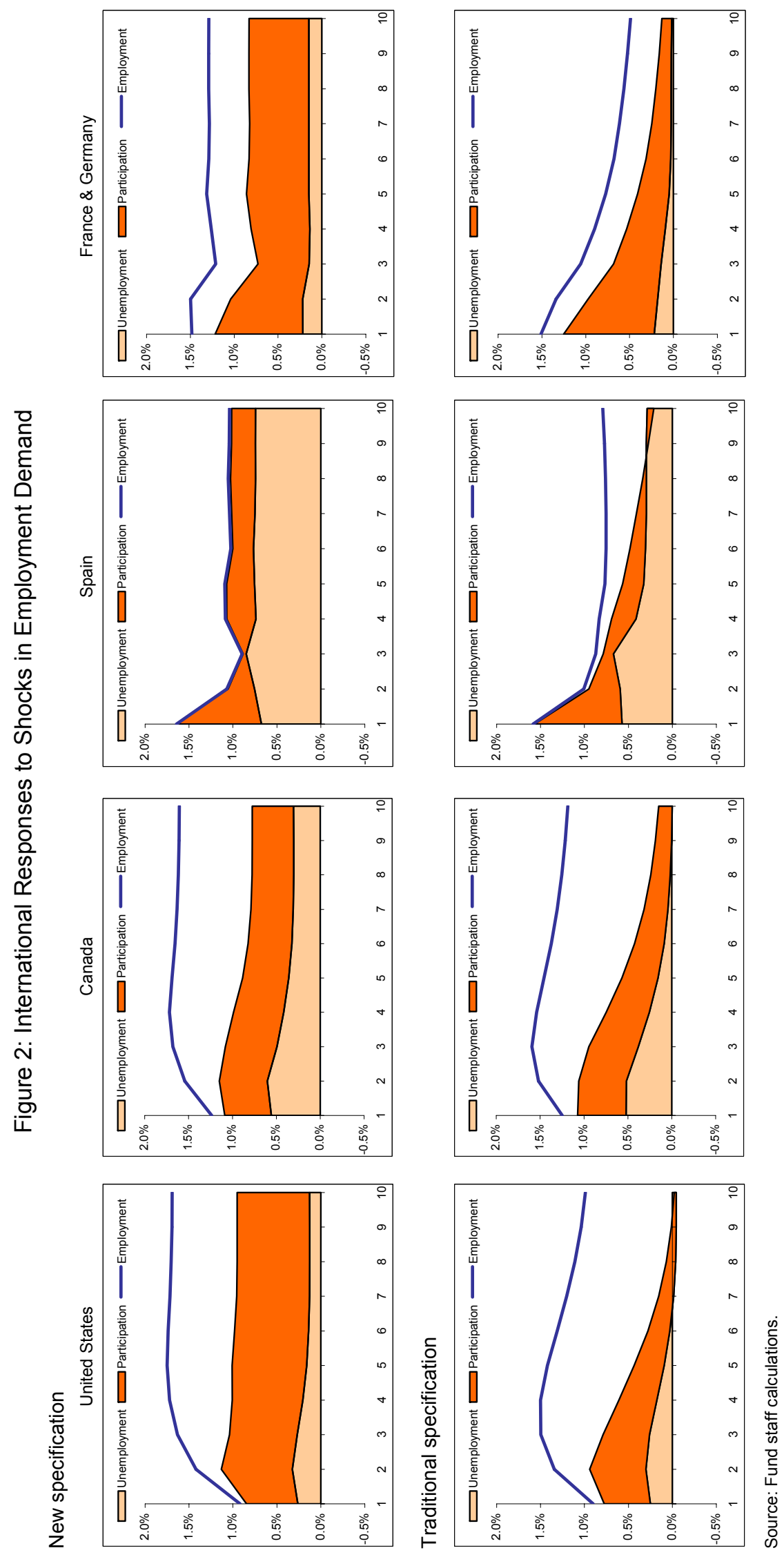

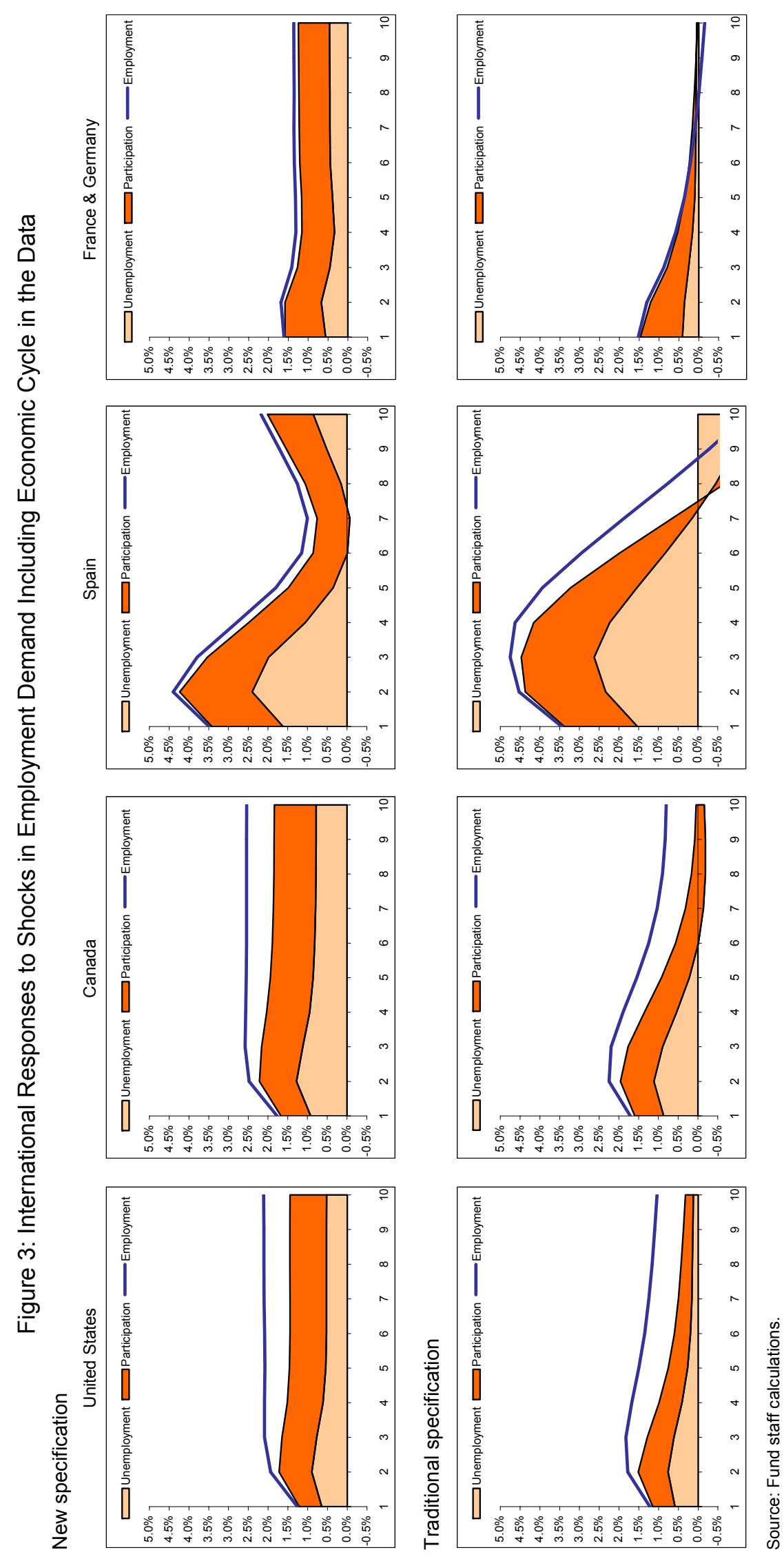

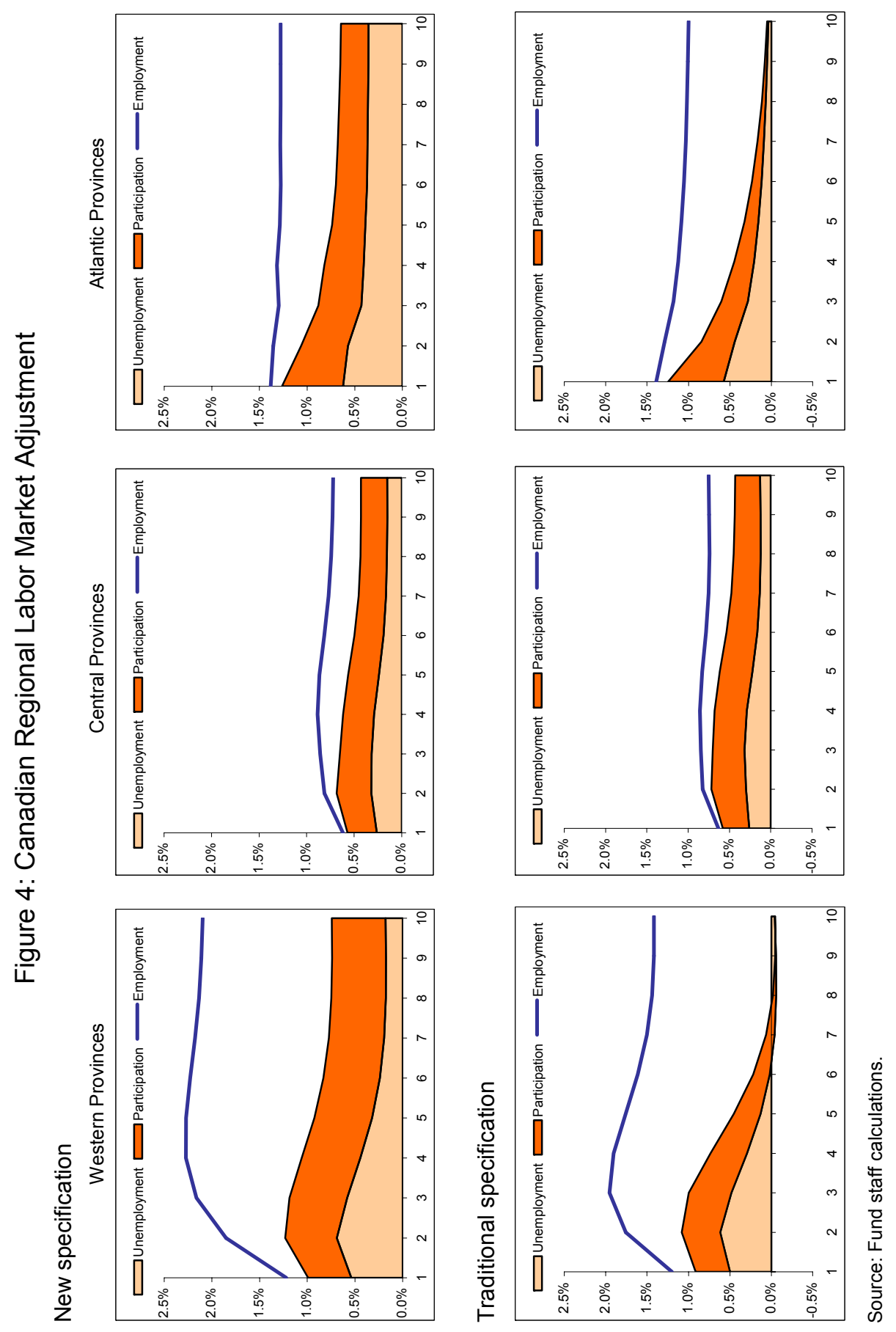

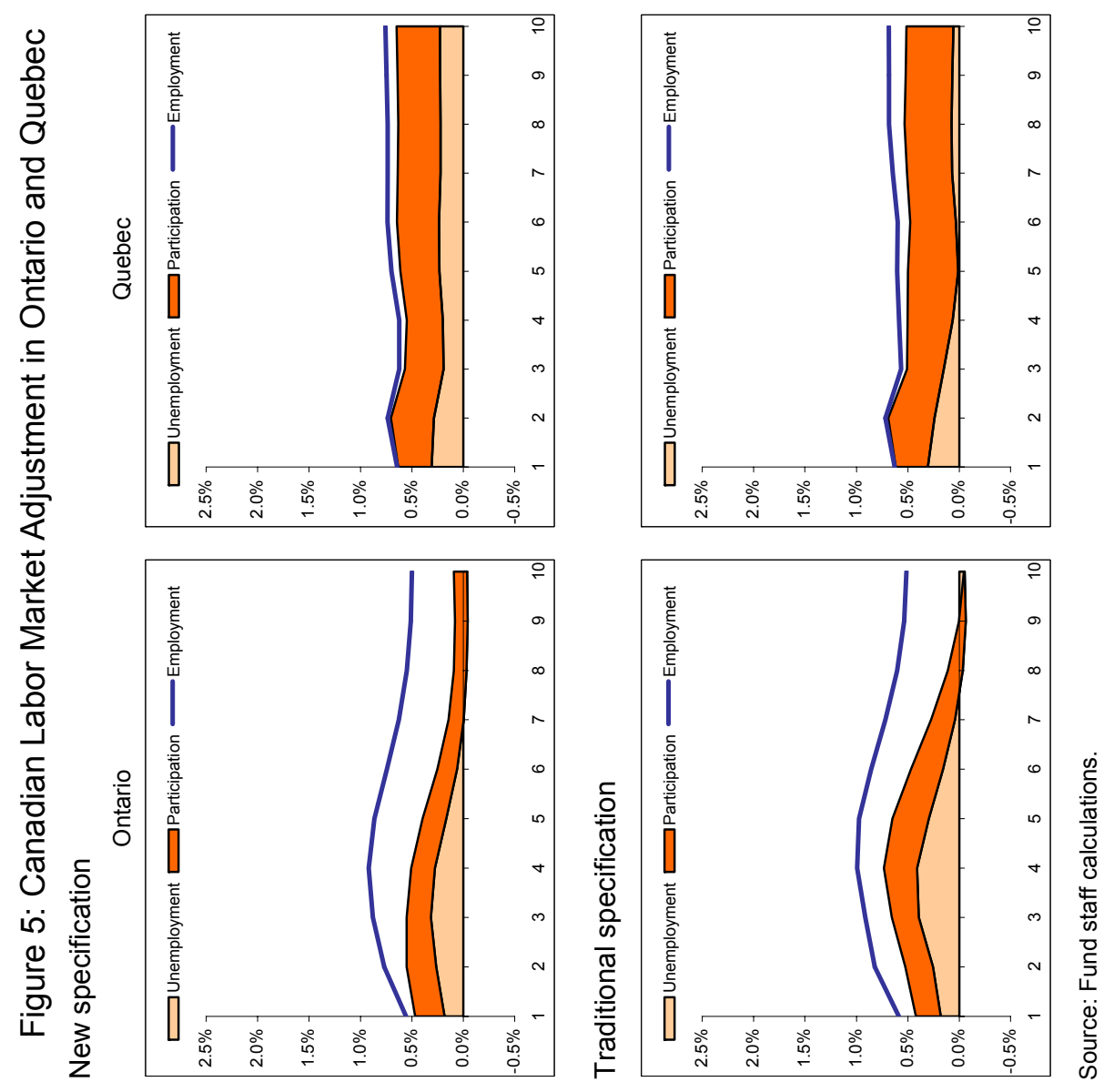


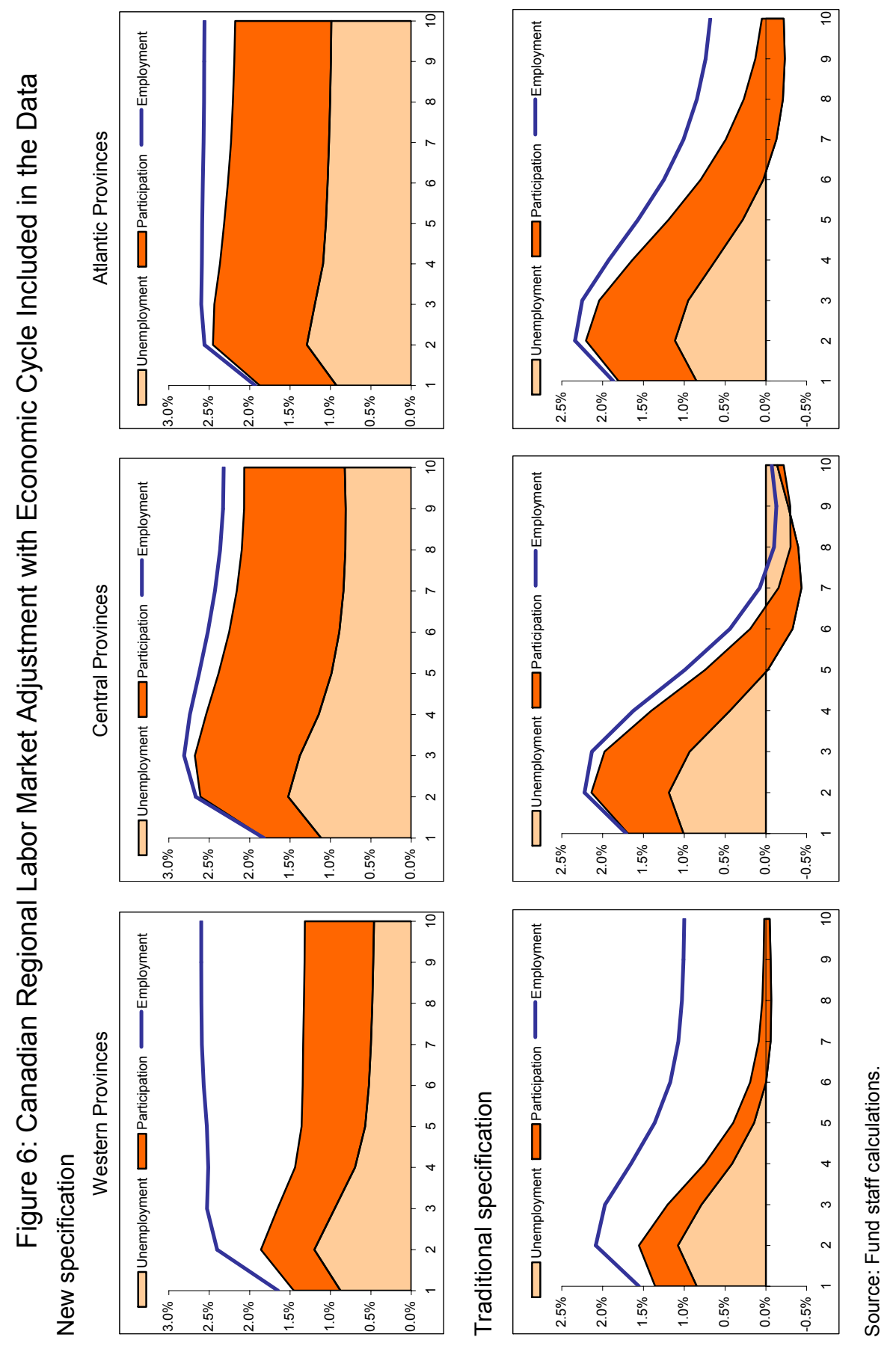




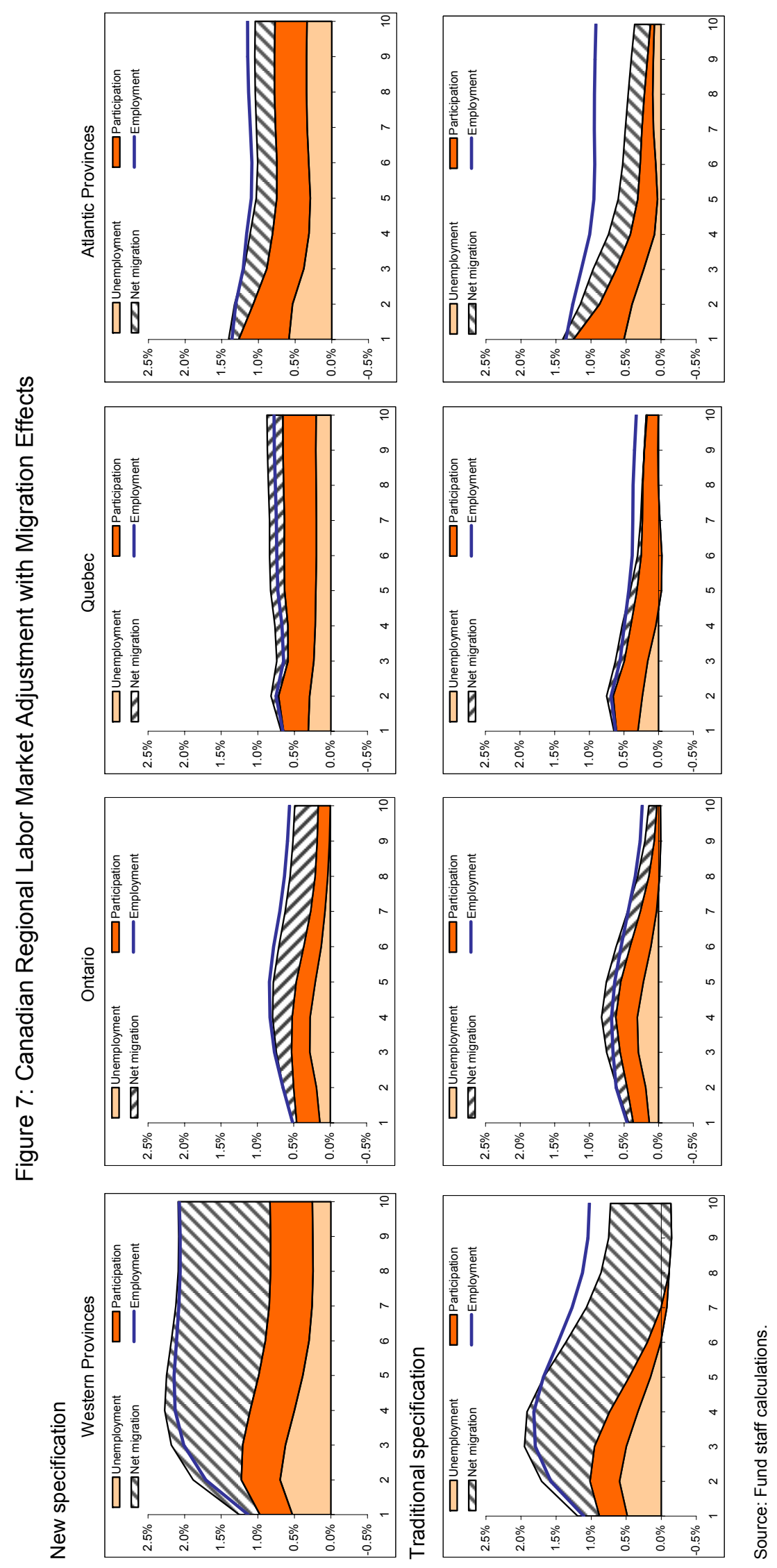



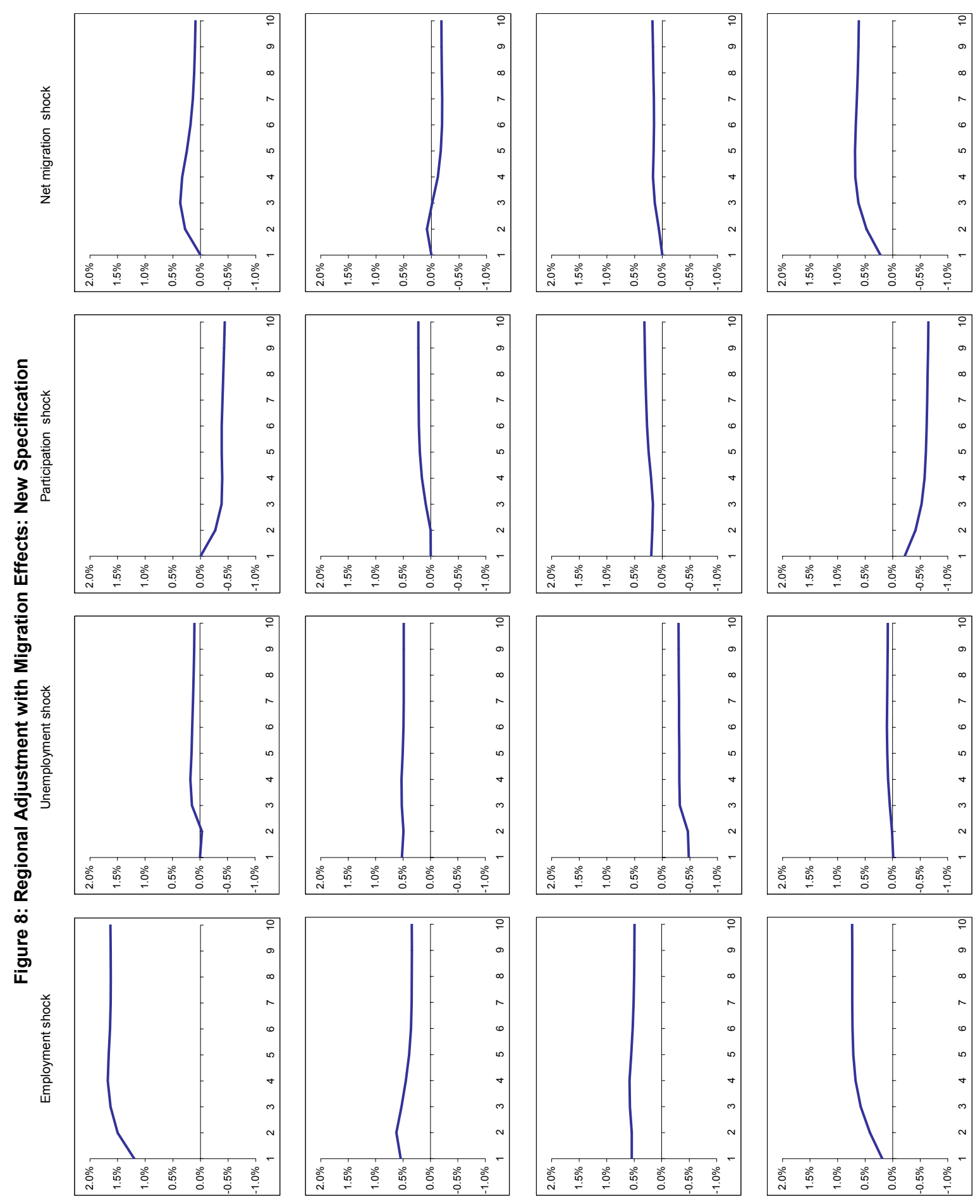

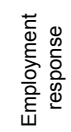
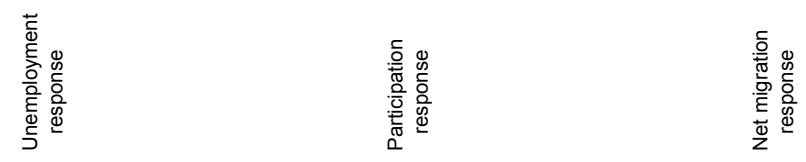

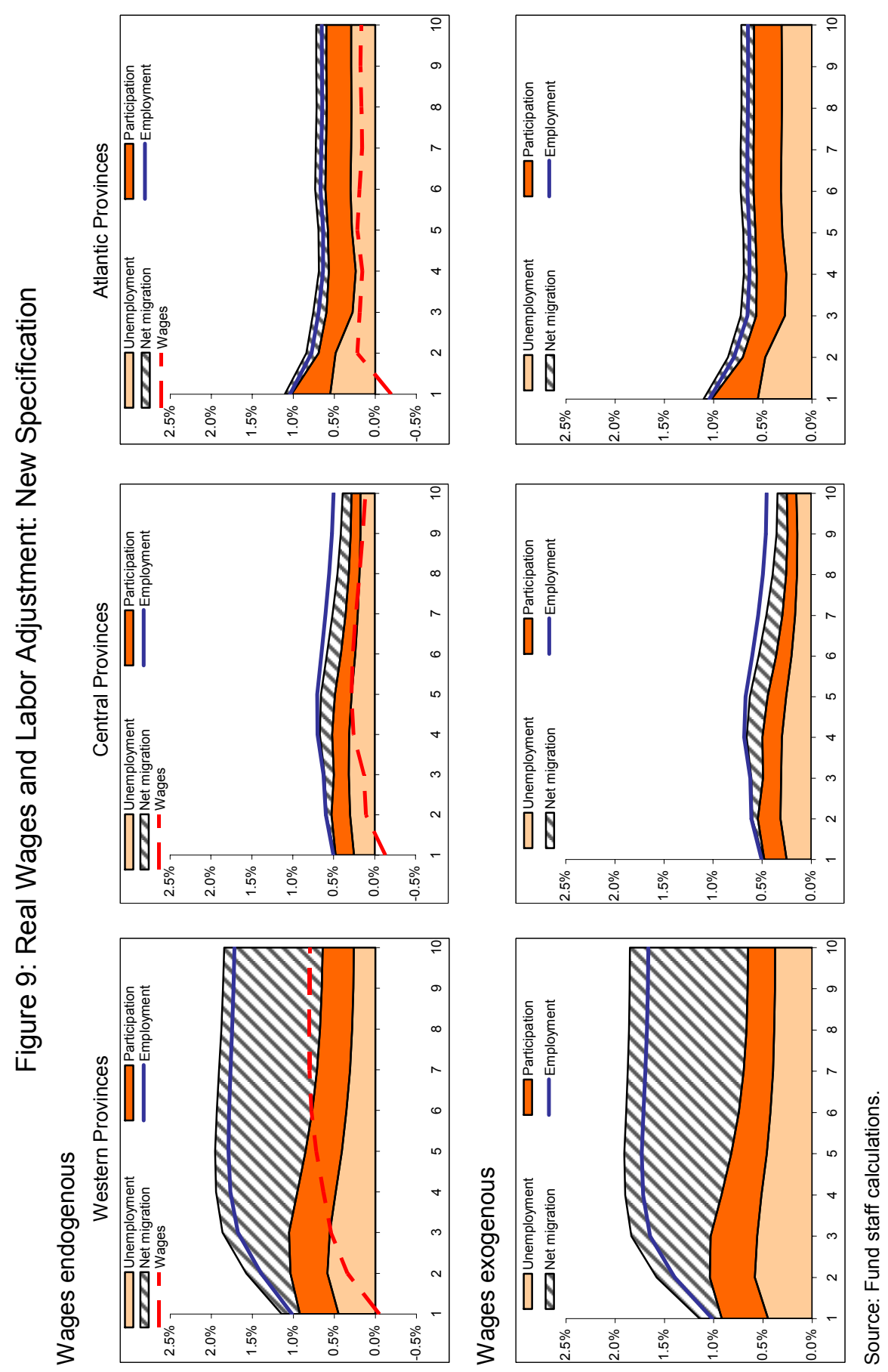
Figure 10: External Shocks and Labor Adjustment: New Specification

Non-energy commodity price shock

\section{Western Provinces}

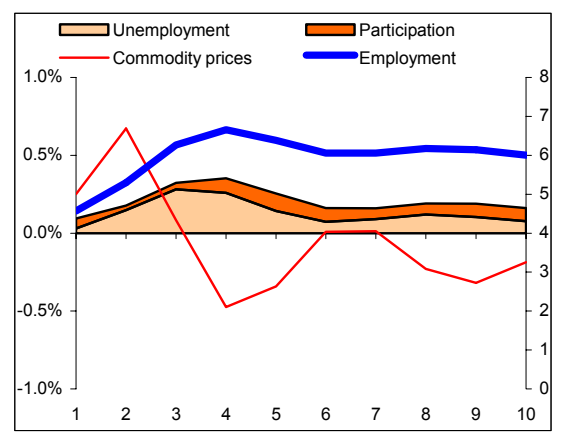

Energy commodity price shock

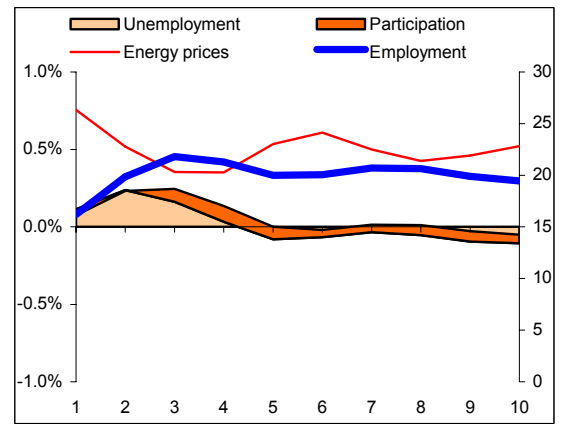

Central Provinces
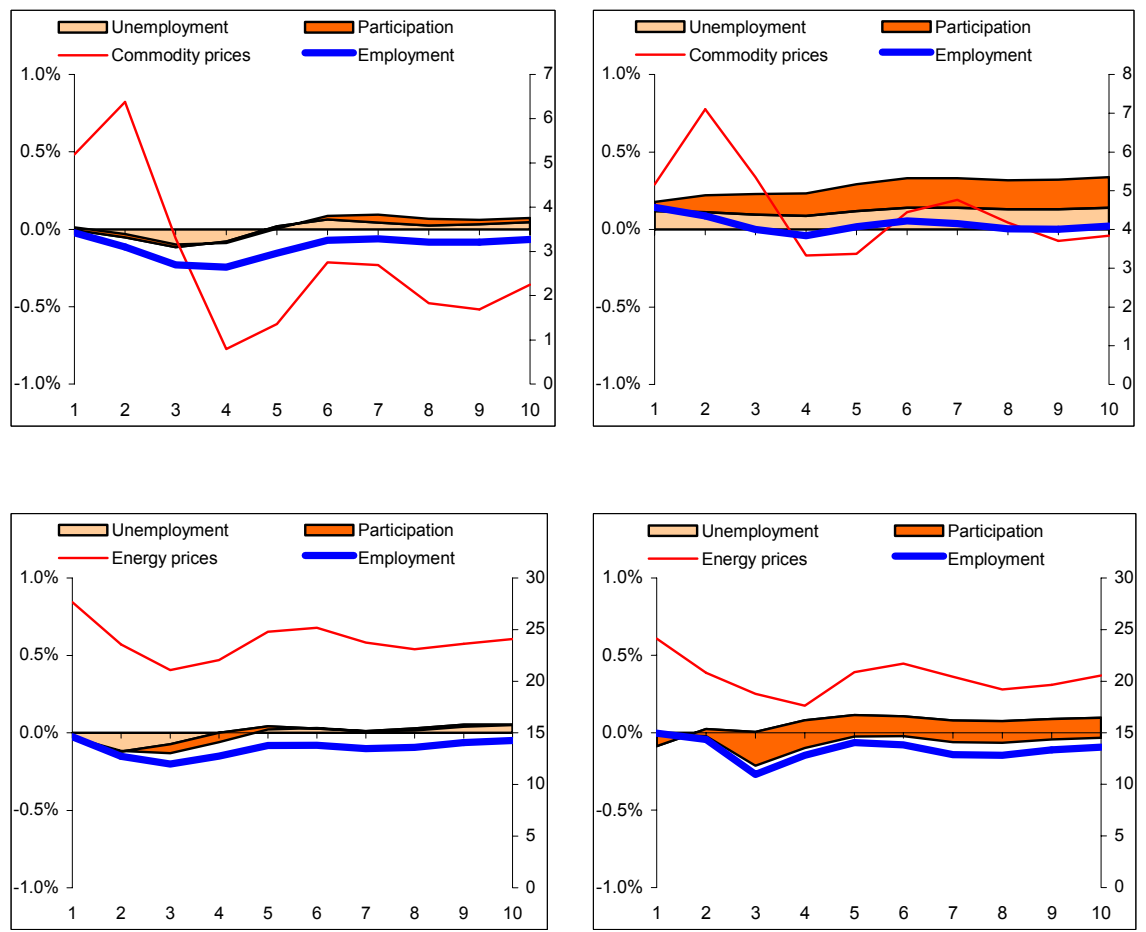

Exchange rate shock unconnected to commodity prices
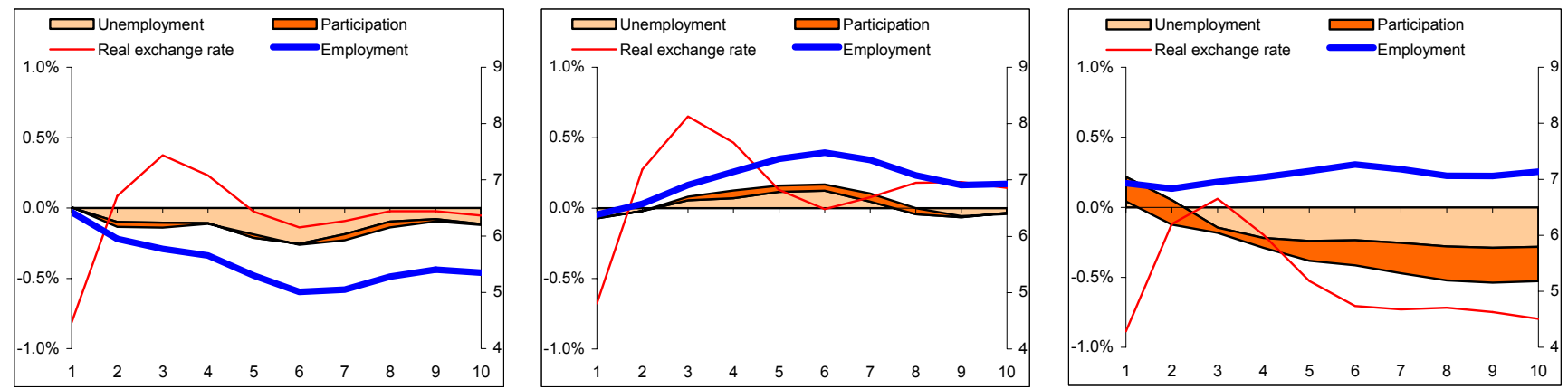

Other demand shocks
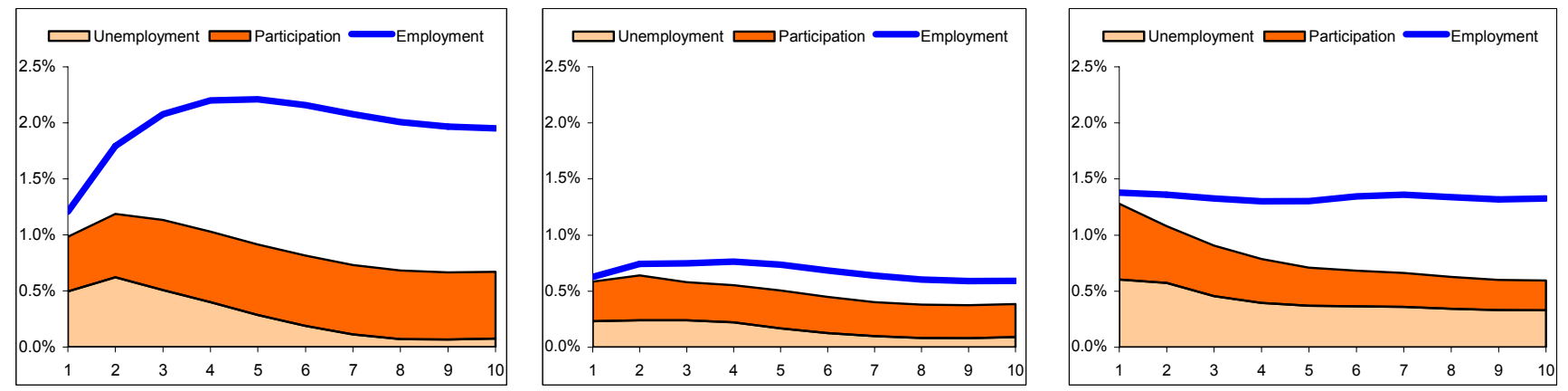

Source: Fund staff calculations. 


\section{Data Appendix}

\section{United States}

Panel: Fifty states plus the District of Columbia.

\section{Data sources:}

labor force

employment

unemployment

unemployment rate

population aged 16-64

labor force participation rate

\author{
Bureau of Labor Statistics \\ Bureau of Labor Statistics \\ Bureau of Labor Statistics \\ Bureau of Labor Statistics \\ = labor force / labor force participation rate $/ 100$ \\ Bureau of Labor Statistics
}

\section{Canada}

National panel includes 10 provinces: Alberta, British Columbia, Manitoba, New Brunswick,

Newfoundland \& Labrador, Nova Scotia, Ontario, Prince Edward Island, Quebec, and Saskatchewan.

Western panel includes: Alberta, British Columbia, and Manitoba.

Central panel includes: Ontario and Quebec.

Atlantic panel includes: New Brunswick, Newfoundland \& Labrador, Nova Scotia, and Prince Edward Island.

\section{Data sources:}

labor force

employment

unemployment

unemployment rate

population aged 15-64

domestic migration

labor force participation rate

total population

personal income

average hourly wages

Statistics Canada
Statistics Canada
Statistics Canada
Statistics Canada
Statistics Canada
Statistics Canada
Statistics Canada
Statistics Canada
Statistics Canada
Statistics Canada

\section{Europe}

French panel includes 8 regions: Bassin Parisien, Centre-Est, Est, Isle de France, Mediterraneo,

Nord - Pas-de-Calais, Ouest, and Sud-Ouest.

German panel includes 17 regions: Bayern, Baden-Wittemberg, Berlin, Brandenburg, Bremen, Hamburg,

Hessen, Mecklenburg-Vorpommern, Niedersachsen, Nordrhein-Westfalen, Rheinland-Pfalz, Saarland,

Sachsen, Sachsen-Anhalt, Schleswig-Holstein, Sonneberg, and Thuingen.

Spanish panel includes 7 regions: Canarias, Centro, Este, Comunidad de Madrid, Noreste, Noroeste, and Sur.

\section{Data sources:}

labor force

employment

unemployment

unemployment rate

population aged 15-64

labor force participation rate

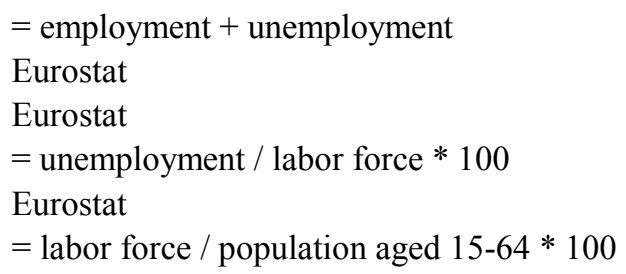

